\title{
DROGAS CITOSTÁTICAS: MEDIDAS PARA MINIMIZAÇÃO DO RISCO OCUPACIONAL*
}

Anadergh Barbosa**

\begin{abstract}
RESUMO - As drogas citostáticas são substâncias citotóxicas destinadas a causar disfunsão celular. Seu mecanismo de ação envolve interação com DNA, RNA na síntese proteica de células vivas, normais ou cancerosas. São também atribuídos a elas um potencial para mutagenicidade, carcinogenicidade, assim como efeitos teratogênicos. Alguns trabalhadores hospitalares estão potencialmente expostos a essas drogas. Propõe-se recomendações para minimizar os riscos ocupacionais causados pelas mesmas, apresentando algumas medidas de controle relativamente simples, de forma a adequarem-se à realidade da maioria dos hospitais brasileiros.
\end{abstract}

\begin{abstract}
The cytostatic drugs are cytostatoxic substances and $c$ 'эsigned to cause cell dysfunction. Their mechanism of action involves interaction with DNA, RNA on protein synthesis in living cells, normal or cancerous. Though these actions the potencial for mutagenic, carcinogenic or teratogenic effects are possible. Some people who work in hospital are frequentely exposed to these drugs. Recomended have done to minimized the occupational risks that produced by then, some forms to control a little simple are showed to adapt to reality of the majority of Brasilian hospital.
\end{abstract}

\section{INTRODUC̣ÃO}

Os profissionais da área da saúde, na maioria das vezes, têm sua atenção voltada totalmente para a assistência ao cliente, deixando não raras vezes a sua saúde e segurança em segundo plano.

As drogas citostáticas vieram a ser preocupação no campo da Saúde Ocupacional há bem pouco tempo (VAINIO, 1982) e, no Brasil essa preocupação é extremamente tímida ainda. Sabe-se que tais drogas são substâncias citotóxicas, designadas a causar disfunção celular. Seu mecanismo de ação envolve interação com o DNA e RNA, ou na síntese proteica em células normais ou cancerosas (VAUGHN \& CHRISTENSEN, 1985). 1985).

Até 1979 os agentes citostáticos eram manuseados sem nenhuma medida de proteção (NIKULA et alii, 1984), apesar de já em 1949 ter-se reconhecido a Mostarda Nitrogenada $\left(\mathrm{HN}_{2}\right)$ como agente carcinogênico e, em 1954, o Trietilenemelamine (VAINIO, 1982).
Vários estudiosos estrangeiros têm pesquisado os possíveis ef eitos das drogas antineoplásicas, usadas no tratamento de cãncer, sobre a saúde das pessoas que manipulam, preparam e administram tais substãncias. (FALCK et alii, 1979; NEAL et alii, 1983; NIKULA et alii, 1984; TORTORICI, 1980).

Os resultados não são totalmente conclusivos, em grande parte devido à impossibilidade de pesquisas experimentais com tais drogas em humanos, porém os resultados encontrados em pesquisas com animais e em grupos de profissionais expostos ocupacionalmente, alerta-nos para os possíveis riscos, principalmente devido à gravidade dos danos e à cronicidade dos mesmos.

Os principais riscos atribuídos a essas drogas são as alterações cromossõmicas (NIKULA et alii, 1984; SIEBER \& ADAMSON, 1975), freqüência aumentada de troca de Cromátide-irmã (NORPA et alii, 1980; SIEBER \& ADAMSON, 1975; VAINIO, 1982), carcinogênese (HARRISON, 1981; SIEBER \& ADAMSON, 1975; TORTORICI, 1982), oligospermia e azooespermia (SIEBER

\footnotetext{
* Trabalho apresentado no III Encontro Nacional de Enfermeiros do Trabalho - São Paulo - SI

** Enfermeira do CEDRHUS - Divisão de Segurança, Higiene e Medicina do Trabalho - FHDF
} 
\& ADAMSON, 1975) sendo as principais forma de contaminação através da inalação de aerosóis e absorção através da pele (VAUGHN \& CHRISTENSEN, 1985).

\section{DESENVOLVIMENTO}

Em pesquisa realizada sobre a avaliação da concentração de agentes antineoplásicos nas áreas de preparo (NEAL et alii, 1983), encontrou-se resultados que sugerem que as pessoas que administram agentes antineoplásicos estão sujeitas à absorção sistêmica potencial por inalação, principalmente devido ao uso de equipamento indevido.

Estudiosos finlandeses (NIKULA et alii, 1984), após pesquisarem aberraçōes cromossômicas em linfócitos de 11 enfermeiras de oncologia, encontraram resultados que sugerem que doses mesmo aparentemente pequenas de drogas citostáticas podem alterar material genético. SIEBER \& ADAMSON (1975), após analisarem extensa revisão de literatura, concluíram que os agentes quimioterápicos em humanos podem induzir aberrações cromossômicas, infertilidade, malformações congênitas, e podem ser potencialmente carcinogênico. Esses mesmos autores alertam para o uso da quimioterapia durante a gravidez poder causar prematuridade, más formações congênitas, incluindo hérnia inguinal, fenda palatina e ausência dos dedos dos pés. Os ef eitos dos riscos ficam mais graves quando da associação de mais de uma droga, ou do uso de quimioterapia associada à radioterapia (SIEBER and ADAMSON, 1975). Diante disto alguns países elaboraram linhas-guias para orientação aos profissionais que manuseiam de alguma forma essas substâncias (DAVIS, 1981; HARRISON, 1981; HOFFMAN, 1980; VAUGHN \& CHRISTENSEN, 1985).

A Sociedade de Farmacêuticos Hospitalares da Austrália (SHPA) (DAVIS, 1981), preocupada com os ef eitos mutagênicos e supostamente carginogênicos das drogas citostáticas sobre a saúde dos profissionais que lidam com tais drogas, elaboraram linhas-guias, visando uma maior conscientização dos riscos envolvidos em tais atividades, assim como recomendações de procedimentos básicos de segurança.

Na tentativa de adequar tais recomendações à realidade dos hospitais brasileiros utilizou-se as orientações e recomendações da SHPA como esqueleto para elaboração de algumas sugestões c'e procedimentos para minimizar o risco químico ocupacional.

No Brasil o desconhecimento dos riscos causados por tais drogas é efetivo, daí a necessidade de uma orientação simples e acessível à realidade dos hospitais brasileiros. Tem-se consciência de que o que se propõe neste ensaio não é o ideal, porém, ante a inviabilidade do ideal, tenta-se minimizar ao máximo os riscos a que estão sujeitos os trabalhadores.

Para o preparo, transporte, administração e desti- no final dos resíduos sólidos recomenda-se que: - Deverá ser selecionada uma pequena área física, separada das demais dependências do setor para o preparo das drogas citostáticas, de modo que o operador fique sujeito a um mínimo de interrupções. A área deve ser exclusiva para o preparo dessas drogas.

- E fundamental que esta área contenha uma pia com água corrente e frascos de soro fisiológico (solução de Cloreto de Sódio a $0,9 \%$ ) para remoção imediata de possíveis derrames destas drogas na pele e nos olhos desprotegidos.

- Devido ao alto custo de se dedicar equipamento sofisticado de fluxo de ar laminar vertical ao preparo de drogas citostáticas, idealizou-se um pequeno armário em acrílico transparente fechado, ligado a um exaustor, possuindo duas "janelas" para entrada das mãos e do material a ser preparado. Essas janelas deverão ser abertas apenas no momento do preparo da droga. (Vide anexo 1).

- Devem ser colocados dois receptáculos descartáveis dentro do armário, sendo um menor co um chumaço de gase para aspirar o excesso de solução injetada, e um maior para depósito dos frascos e esfregaços usados no preparo da droga com vistas a posterior destruição.

- Para o preparo dessas drogas o operador deve usar avental plástico de mangas compridas, se possível descartável, luvas de cloreto polivinil, máscara e óculos deproteção além de todas as outras medidas de higiêne para o preparo de qualquer droga, como cabelos presos, por exemplo.

- Os gargalos das ampolas devem ser sempre envoltos em esfregaços (gase) estéreis para serem quebrados, de forma a evitar possíveis acidentes (cortes).

- Deve-se evitar ao máximo produção de aerossóis em todas as ocasiōes.

- Recomenda-se o uso de seringas com capacidade sempre maior do que o volume da droga a ser preparada, de forma que a seringa fique com no mínimo uma margem 1/3 de sua capacidade livre.

- Devem ser usadas sempre agulhas de grande calibre para evitar injeção sob alta pressão.

- Conjuntos de infusão intravenosa devem ser montados com particular cuidado para evitar vazamentos e conseqüentemente contaminaçào.

- Caso ocorra derrame destas drogas na pele ou nos olhos desprotegidos, ação imediata deve ser tomada para remover o material por lavagem com grandes volumes de água ou solução de cloreto de sódio a (0,9\%. - Após preparadas, as drogas devem ser transportadas em bandejas forradas com plástico, de modo que ao final do procedimento, o plástico possa ser cuidadosamente removido, como dejeto de alto risco.

- Pós liofilizados (secos por congelamento) em ampolas de vidro são considerados especialmente perigosos, pois partículas da droga podem ser liberadas quando as ampolas são quebradas. Diluentes deveriam ser len- 
tamente introduzidos pela parede da ampola abaixo, para assegurar que o pó esteja completamente molhado, antes de proceder qualquer agitação. Ampolas enchidas com líquido de agentes citostáticos podem produzir aerossóis ao serem abertas.

- Empacotamento impermeável deve ser empregado para preparar dosagens completas para transporte à enfermaria.

- Urina, vômitos e outros fluidos corporais de pacientes recebendo drogas citostáticas devem ser tratados como materiais potencialmente mutagênicos. Roupas contaminadas com taix excretas devem constituir dejetos de alto risco.

- Instalações devem ser supridas para a coleta e armazenamento, para incineração segura e separada, de todas as seringas, frascos, e outros materiais que estiverem em contato com drogas citostáticas. Cuidado particular deve ser tomado para proteger o pessoal do descarte contra objetos afiados, como agulhas e ampolas quebradas. Esses itens devem ser considerados como objetos de alto risco, devendo ser tomado cuidado para se evitar acondicioná-los em recipientes totalmente fechados que poderiam explodir dentro do incenerador. Temperaturas próximas dos $1000^{\circ} \mathrm{C}$ podem ser necessárias para inativar substâncias citotóxicas. - É importante a identificação de todo material que entra em contato com a droga como "material de alto risco" ou "contaminado - Quimioterapia", inclusive roupas de cama de uso do paciente em tratamento quimioterápico.

- Todo profissional que entra em contato direta ou indiretamente com drogas citostáticos ou com excretas de pacientes em uso destas, deve receber treinamento siste natizado sobre os riscos que corre e as possíveis formas de prevenção.

- Manuais de procedimentos e linhas de ação deveriam ser produzidos e distribuídos a todos os profissionais que trabalham direta ou indiretamente com essas drogas.

- O preparo de drogas citostáticas deve ser o mais centralizado possível, e envolver o menor número de pessoas, de forma que tais operadores possam ser altamente treinados e conscientizados dos riscos envolvidos na operação.

- Avaliar periodicamente a efetividade das medidas adotadas. Uma das formas de avaliar a possível exposição a agentes mutagênicos e carcinogênicos é avaliar o dano cromossômico e a troca de cromátide irmã em linfócitos periféricos do sangue das pessoas expostas (VAINIO, 1982).

\section{CONCLUSÃO}

Tais recomendações não vão solucionar a questão dos riscos ocupacionais por quimioterápicos, porém, se seguidas, amenizarão em grande escala as possibilidades de contaminação.

É importante que ao manipular com drogas citostáticas tenha-se sempre a preocupação de proteger: $o$ ambiente, o operador, o paciente e a droga (DAVIS, 1981).

Fica neste ensaio o desafio aos profissionais de saúde e mais especificamente aos de Saúde Ocupacional, de melhorarem tais recomendações, assim como, se responsabilizarem pela divulgação das mesmas através de treinamentos sistematizados aos profissionais envolvidos na operação, e supervisão dos ambientes de preparo, remoção e destino dos resíduos sólidos e orgânicos, contaminados por drogas citostáticas.

\section{REFERÊNCIAS BIBLIOGRÁFICAS}

1. DAVIS, R.M. Guidelines for safe handling of cytotoxic drugs in pharmacy departaments and hospital wards. Hospital Pharmacy, 16: 17-20, jan. 1981

2. FAl, 'K, K. of alii. Mutagenicity of urine of nurses handling (ytostatic drugs. Lancet, 1979 p. 12:)(1)-1.

3. HARRISON, B.R. Developing guidelines for working with antineoplastic drugs. American .Journal Hospital Pharmacy. 38: 1686-93, 1981

4. H(FFMAN, D.M. The handling of antineoplastic drugs in a major ("ancer center. Hospital Pharmacy, 15: 3(12-(1)4, June 1980

5. NEAL, A de W. et alii. Exposure of Hospital worders to Airborne Antineoplastic Agents. American Journal of Hospital Pharmacy. 4(): 587-6()1, 1983

(i. NIKULA, E. et alii. Chromossome aberrations in lymphocytes of nurses handling cytostatic agents. scand J. work ENVIRON HEALTH. 10: 71-4. 1984

7. NORPA, H et alii. Increased sister chromatid exchange frequencies in limphocytes of nurses handling cytostatic drugs. Scand J. work Environ health. 6: 299-301. 1980

8. SIEBER, S.M. \& ADAMSON, R. H. Toxicity of Antineoplastic agents in man; Chromossomal Aberrations, anfertility effects, congenital malformations, and carcinogenic potencial. Adv cancer res., 2.2: 57-15.5, 1.975

9. TORTORICI, M.P. Precautions followed by personnel involved with the preparation of parenteral antineoplastic medications. Hospital Pharmacy. 15: 293-301 .June. 1980

10. VAINIO, H. Inhalation anesthetics, anticancer drugs and sterilants as chemical hazards in hospitals. Scand J. Environ Health. 8: 94-107. 1982

11. VAUGHN, M. C. \& CHRISTENSEN. Occupational exposure to (ancer chemotherapeutic drugs: A literature review. American Industrial Hygiene Association. 46, June 1985. 


\section{ANEXO I}

ARMÁRIO PARA PREPARO

DE DROGAS CITOSTÁTICAS

- O armário deve ser instalado junto a uma parede com comunicação externa adaptado a um exaustor, de forma que $o$ ar aspirado do armário seja jogado na atmosfera.

- O armário deve ser instalado numa altura que permita ao funcionário em pé visualizar a operação por sobre o mesmo; e deve ainda localizar-se sob lâmpada fria de alta potência.

- As "janelas" do armário devem permanecer fechadas, exceto durante o preparo das drogas.

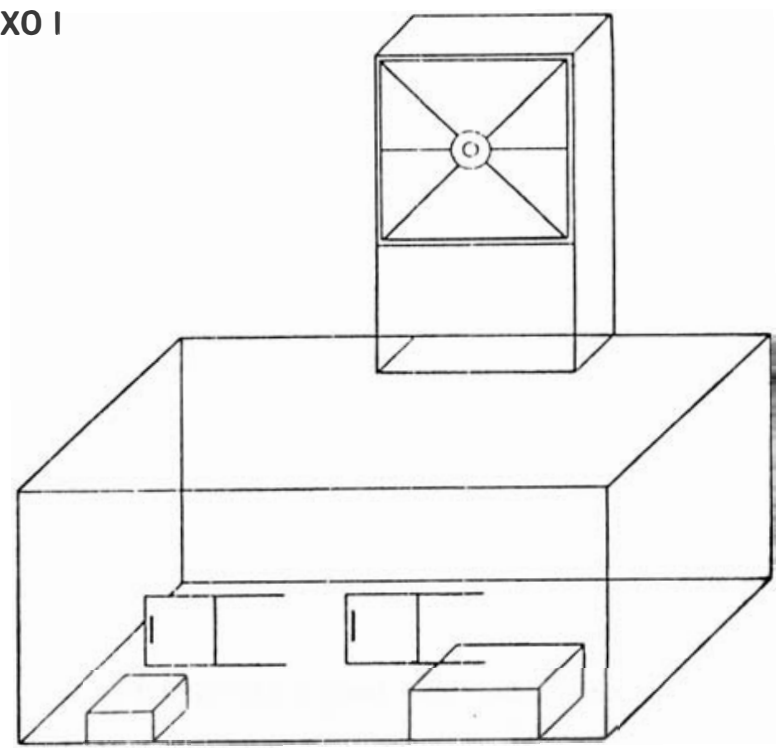

